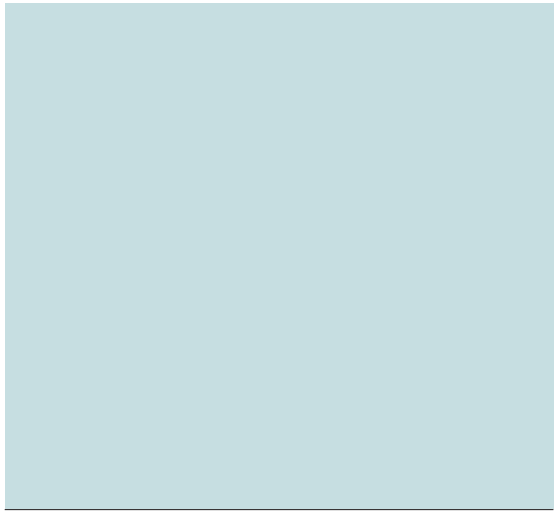

C. Daniel Johnson, MD, MMM

For the Group

\title{
The National CT Colonography
}

Trial: Assessment of Accuracy in Participants 65 Years of Age and

\section{Older $^{1}$}

Purpose:

Materials and Methods:

Results:

Conclusion:
To conduct post-hoc analysis of National CT Colonography Trial data and compare the sensitivity and specificity of computed tomographic (CT) colonography in participants younger than 65 years with those in participants aged 65 years and older.

Of 2600 asymptomatic participants recruited at 15 centers for the trial, 497 were 65 years of age or older. Approval of this HIPAA-compliant study was obtained from the institutional review board of each site, and informed consent was obtained from each subject. Radiologists certified in CT colonography reported lesions $5 \mathrm{~mm}$ in diameter or larger. Screening detection of large $(\geq 10-\mathrm{mm})$ histologically confirmed colorectal neoplasia was the primary end point; screening detection of smaller $(6-9-\mathrm{mm})$ colorectal neoplasia was a secondary end point. The differences in sensitivity and specificity of CT colonography in the two age cohorts (age $<65$ years and age $\geq 65$ years) were estimated with bootstrap confidence intervals (CIs).

Complete data were available for 477 participants 65 years of age or older (among 2531 evaluable participants). Prevalence of adenomas $1 \mathrm{~cm}$ or larger for the older participants versus the younger participants was $6.9 \%$ (33 of $477)$ versus $3.7 \%$ (76 of 2054) $(P<.004)$. For large neoplasms, mean estimates for CT colonography sensitivity and specificity among the older cohort were 0.82 (95\% CI: $0.644,0.944)$ and 0.83 (95\% CI: $0.779,0.883)$, respectively. For large neoplasms in the younger group, CT colonography sensitivity and specificity were 0.92 (95\% CI: 0.837, 0.967) and 0.86 (95\% CI: 0.816, 0.899), respectively. Per-polyp sensitivity for large neoplasms for the older and younger populations was 0.75 (95\% CI: $0.578,0.869)$ and 0.84 (95\% CI: $0.717,0.924)$, respectively. For the older and younger groups, per-participant sensitivity was 0.72 (95\% CI: $0.565,0.854)$ and 0.81 (95\% CI: $0.745,0.882)$ for detecting adenomas $6 \mathrm{~mm}$ in diameter or larger.

For most measures of diagnostic performance and in most subsets, the difference between senior-aged participants and those younger than 65 years was not statistically significant.

${ }^{\circ}$ RSNA, 2012
${ }^{1}$ From the Department of Radiology, Mayo Clinic, 13400 E Shea Blvd, Scottsdale, AZ 85259 (C.D.J.). The complete list of authors and affiliations is at the end of this article. Received November 17, 2010; revision requested December 21; revision received September 16, 2011; accepted October 18; final version accepted

December 8. Address correspondence to C.D.J. 
$\mathbf{T}$ he American College of Radiology Imaging Network, or ACRIN, National CT Colonography Trial (ACRIN 6664), the largest prospective trial reported to date on computed tomographic (CT) colonography, was designed to assess the accuracy of screening CT colonography for identifying participants with histologically confirmed colorectal neoplasia $10 \mathrm{~mm}$ in diameter or larger, with optical colonoscopy as the reference standard (1). The trial recruited 2600 participants from 15 U.S. medical centers. Its results indicated that CT colonography helped identify $90 \%$ of patients with asymptomatic large colorectal adenomas or cancers that were detected with optical colonoscopy. Of the adenomatous polyps $6 \mathrm{~mm}$ or larger, $78 \%$ were detected. Specificity estimates ranged from $86 \%$ to $89 \%$ among lesions $6 \mathrm{~mm}$ or larger. These data indicate that CT colonography performance is similar to that reported for colonoscopy.

Despite these results from the $\mathrm{Na}^{-}$ tional CT Colonography Trial and the acceptance of CT colonography by other national organizations $(2,3)$, the Centers for Medicare and Medicaid Services recently deferred coverage for CT colonography (4). One of the major reasons stated for this coverage denial is the lack of data on CT colonography performance in senior-aged

\section{Advances in Knowledge}

- There was no significant difference in the accuracy of CT colonography for the detection of large and intermediate-sized adenomatous lesions in participants aged 65 years or older compared with that in younger participants; per-participant sensitivity and specificity among the older and younger cohorts were 0.82 and 0.83 and 0.92 and 0.86 , respectively.

- The overall prevalence of large adenomas and cancers was $6.9 \%$, with an overall colonoscopy referral rate of $12.6 \%$ among the older participant population.
Medicare-eligible recipients (4). The purpose of this study was to conduct a post-hoc analysis of National CT Colongraphy Trial data and to compare the diagnostic accuracy of CT colonography in participants 65 years of age and older with that in participants younger than 65 years.

\section{Materials and Methods}

Fifteen sites accredited for this specific multicenter research study by the American College of Radiology Imaging Network participated in this study, which was compliant with the Health Insurance Portability and Accountability Act. Approval was obtained from the institutional review board of each site before study activation. Signed informed consent was obtained from every participant. A total of 2600 consecutive, asymptomatic outpatients aged 50 years or older who were prescheduled to undergo screening colonoscopy were recruited for CT colonography between February 2005 and December 2006 (1). From this study group, a post-hoc subanalysis on the accuracy of CT colonography was performed for 497 participants, identified across all participating sites, who were 65 years of age or older at enrollment. Complete screening data were available for 477 (96\%) of these participants. Same-day CT colonography and colonoscopic examinations were performed for 472 (99\%) of the 477 participants in this subcohort. Comparisons were made between this older subgroup and the younger participants.

Details regarding participant recruitment, the technical conduct of the CT colonography examination and image interpretation, the index colonoscopy examination, radiologist interpretation training and instructions,

\section{Implication for Patient Care}

- CT colonography can be used as a primary colorectal screening tool in patients older than 65 years, as well as in those aged 50-65 years. lesion-matching methods, and statistical analysis have been previously published (1). Participants were recruited among asymptomatic individuals 50 years of age or older who were prescheduled to undergo screening colonoscopy. Prospective participants were excluded if they had melena, hematochezia on more than one occasion in the previous 6 months, lower abdominal pain, inflammatory bowel disease, familial polyposis syndrome, a serious medical condition associated with increased risk of complications from colonoscopy, colonoscopy within the past 5 years, substantial anemia, and/ or a positive fecal occult blood test (1).

\section{Imaging Methods}

In the 477 participants aged 65 years or older, CT colonography examinations were performed with 16 -section scanners for 207 participants (43\%), 40-section scanners for 22 participants (5\%), and 64-section scanners for 248 participants (52\%). For the 2351 main study participants, CT colonography examinations were performed with 16-section scanners for 1140 participants (48\%), 40-section scanners for 83 participants (3\%), and 64-section scanners for 1308 participants $(52 \%)$. This comparison indicates that there was no appreciable difference between the full cohort and the older-than-65-years subset in terms of the scanner used.

CT images were obtained with GE Healthcare, Siemens Medical Systems, Philips Medical Systems, and Toshiba scanners. Radiologists used two-dimensional interpretation and three-dimensional problem solving to make 240

\section{Published online before print} 10.1148/radiol.12102177 Content code: GI

Radiology 2012; 263:401-408

Abbreviation:

$\mathrm{Cl}=$ confidence interval

\section{Funding:}

This research was supported by the National Institutes of Health (grant NCT00084929).

Potential conflicts of interest are listed at the end of this article. 
interpretations and used primary threedimensional endoluminal flythrough and two-dimensional problem solving to make 237 interpretations. CT colonography software included Innerview GI (Vital Images, Plymouth, Minn), Advantage CT colonography (GE Healthcare, Chalfont St Giles, England), syngo colonography (Siemens Medical Solutions, Malvern, Penn), v3d (Viatronix, Stony Brook, NY), and Aquarius Workstation (TeraRecon, San Mateo, Calif).

Residual fluid and stool and colon distention were rated by the radiologist on a four-point scale. Ratings for fluid were no fluid, minimal fluid, moderate fluid $(<50 \%$ of the colon lumen filled), and $50 \%$ or greater luminal filling. Ratings for residual stool were no stool, small particles present (did not compromise study), moderate amount of solid stool (diagnostic study possible), and lumen full of liquid stool (nondiagnostic study). Ratings for distention were entire segment visualized and well distended, entire segment visualized but underdistended, segment poorly visualized, and segment collapsed. The prevalence and clinical importance of extracolonic findings are reported for both age groups.

\section{Statistical Analysis}

The analysis was exploratory and was not included or powered in the original analytic plan. We followed the analytic approach of the primary study (1) but focused on the comparison of diagnostic accuracy in the subset of Medicare-aged participants (age, $\geq 65$ years) with that in participants younger than 65 years.

The reference standard was defined in the same manner as in the primary study-on the basis of colonoscopic findings and pathologic examination of tissue specimens to determine size and histologic factors. Similarly, a test result was defined as positive when the reader identified a CT colonography lesion with a diameter of $5 \mathrm{~mm}$ or greater. For the purposes of estimating diagnostic and predictive performance measures, participants were considered to have truepositive findings when they had a positive CT colonography result and one or more positive lesions as determined by using the reference standard. Otherwise, they were considered to have false-positive findings. A lesion was considered truepositive when a CT colonography test lesion matched a reference-standard lesion of the specified size.

For each of the two age subgroups, estimates of sensitivity, specificity, and positive and negative predictive values were derived at the participant level, for each reader separately, and for each threshold of lesion size from 5 to $10 \mathrm{~mm}$. For example, the sensitivity of a particular reader in the subgroup of participants younger than 65 years was estimated as the percentage of participants in that subgroup with true-positive lesions at CT colonography among those with pathologically documented lesions of a given size or greater. For each measure of diagnostic or predictive accuracy, the average across all readers was computed according to age subgroup also.

Comparison of accuracy measures between the two age subgroups was performed with bootstrap confidence intervals (CIs) computed for subset averages and the difference. The bootstrap method was used to account for correlations in the data because the same readers interpreted the scans in participants in both age subgroups. For each comparison, 10000 bootstrap samples were selected with replacement from the group of readers, and CIs were computed with appropriate equal-tailed percentiles of the empirical distribution of the bootstrap $P$ values (5). A particular difference was termed significant if the corresponding CI did not include 0 . We report 95\% CIs for each difference in average accuracy measure. To determine whether a significant difference existed at the $95 \%$ confidence level, we used a Bonferroni adjustment and indicated whether the $99 \%$ CI for the comparison contained 0 .

In addition to comparisons of accuracy measures estimated at the participant level, we compared the two age groups on the basis of sensitivity estimated at the polyp level. The analytic approach was similar to that followed in the participant-level analysis. We also examined whether age was related to the location of lesions in the colon. For descriptive purposes, we tabulated lesions according to each of the six colon segments and computed percentages according to age group. For analysis purposes, we grouped segments into left (rectum, sigmoid, and descending) and right (transverse, ascending, and cecum) regions. The relation of age to region was examined through a logistic model with generalized estimating equations to account for the fact that a participant subgroup had both left- and right-region lesions. The analysis was generated with statistical software (SAS, version 9; SAS Institute, Cary, NC). The original sample size was computed to provide an adequate number of participants with lesions $10 \mathrm{~mm}$ in diameter or larger, to ensure that the standard error of the average sensitivity was less than 0.05. The design of the larger study did not address the needs for statistical precision in subset analyses, such as the one reported in the present article.

\section{Results}

There was a total of 2600 recruited participants, of whom 497 (19\%) were 65 years of age or older at enrollment. Complete CT colonography and optical colonoscopy results were available for 477 participants (96\%) in this age group. The younger cohort contained 2103 participants less than 65 years of age, of whom 2054 (98\%) had colonoscopy results available. These participants constituted the study set. Table 1 provides complete demographic data for the two participant cohorts. Among the older participants, 423 (89\%) had no known colorectal cancer risk factors other than age, 35 (7\%) had a firstdegree relative with a history of colorectal polyps or cancer, 17 (4\%) had a personal history of polyps or cancer, and two $(<1 \%)$ had both. All other participants were considered at average risk for colorectal cancer screening purposes. Overall, a medical history of polyps or colon cancer was more frequent in the older cohort $(P<.001)$. Characteristics of sex and race and ethnicity were similar between cohorts. 


\section{Individual Participant Assessment}

Estimates of the measures of diagnostic and predictive performance of CT colonography in the two age groups for detecting participants with one or more adenomas or cancer of $5 \mathrm{~mm}$ or larger are shown in Table 2. For the older cohort, the mean sensitivity, specificity, positive predictive value, and negative predictive value for adenomas or cancers of $10 \mathrm{~mm}$ or larger were 0.82 (95\% CI: $0.644,0.944), 0.83$ (95\% CI: 0.779 , 0.883 ), 0.33 (95\% CI: $0.216,0.459)$, and 0.98 (95\% CI: $0.972,0.995)$, respectively. For participants younger than 65 years, the sensitivity, specificity, positive predictive value, and negative predictive value for adenomas or cancers of $10 \mathrm{~mm}$ or larger were 0.92 (95\% CI: 0.837, 0.967), 0.86 (95\% CI: $0.816,0.899), 0.20$ (95\% CI: 0.154 , 0.253 ), and 0.996 (95\% CI: 0.993, $0.999)$, respectively.

In the older cohort, per-participant sensitivity for adenomas with maximal diameters of $5,6,7,8$, and $9 \mathrm{~mm}$, respectively, was $0.60,0.72,0.77,0.77$, and 0.82 , compared with $0.67,0.81$, $0.84,0.87$, and 0.91 for the younger age group. Specificity estimates ranged from 0.83 to 0.86 for the older age group and from 0.86 to 0.89 for the younger age group. Sensitivity for individual readers varied from $0 \%$ to $100 \%$, with nine $(64 \%)$ of 14 radiologists discovering all of the participants with large adenomas and one radiologist registering no participants 65 years of age or older with a lesion $10 \mathrm{~mm}$ or larger. The 95\% CIs for the difference in average sensitivity or specificity between the two cohorts included 0 for the $10-\mathrm{mm}$ threshold analysis, indicating no significant difference. This result was also the case for all other threshold analyses except in comparison of specificities for the 8-mm threshold. Intervals on the average difference in positive predictive value also included 0 for all thresholds. However, the negative predictive value was consistently higher in participants younger than 65 years of age for all thresholds, as indicated by the fact that all 95\% CIs for the difference in negative predictive value were less than 0 .

\begin{tabular}{|c|c|c|}
\hline \multicolumn{3}{|c|}{ Comparison of Overall Characteristics of Study Participants according to Age Group } \\
\hline Characteristic & $\begin{array}{l}\text { Patients Aged < } 65 \text { y } \\
(n=2054)\end{array}$ & $\begin{array}{l}\text { Patients Aged } \geq 65 y \\
(n=477)\end{array}$ \\
\hline Age at enrollment $(y)^{*}$ & $55.6(52-59)$ & $69.8(66-86)$ \\
\hline \multicolumn{3}{|l|}{ Sex } \\
\hline Male & $965(47)$ & $240(50)$ \\
\hline Female & $1089(53)$ & $237(50)$ \\
\hline \multicolumn{3}{|l|}{ Race or ethnic group ${ }^{\dagger}$} \\
\hline American Indian or Alaskan Native & $20(1)$ & $3(1)$ \\
\hline Asian & $48(2)$ & $11(2)$ \\
\hline Black & $277(13)$ & $56(12)$ \\
\hline Native Hawaiian or other Pacific Islander & $7(21)$ & 0 \\
\hline White & $1689(82)$ & $402(84)$ \\
\hline Unknown or data missing & $40(2)$ & $6(1)$ \\
\hline \multicolumn{3}{|l|}{ Hispanic or Latino ethnicity } \\
\hline No & $1973(96)$ & 457 (96) \\
\hline Yes & $77(4)$ & $20(4)$ \\
\hline Unknown & $4(<1)$ & 0 \\
\hline \multicolumn{3}{|l|}{ Medical history of polyps or colon cancer } \\
\hline Family history & $200(10)$ & $35(7)$ \\
\hline Personal history & $17(1)$ & $17(4)$ \\
\hline Both family and personal history & $11(1)$ & $2(<1)$ \\
\hline
\end{tabular}

Note.-Unless otherwise specified, data are numbers of participants, with percentages in parentheses. Percentages may not add up to $100 \%$ because of rounding

* Data are means, with interquartile ranges in parentheses.

${ }^{\dagger}$ Race or ethnic group was self reported; more than one race or ethnic group may have been reported by a participant.

The distribution and the histologic factors of the lesions $10 \mathrm{~mm}$ or greater found at colonoscopy in both age subcohorts are listed in Table 3. In the older group, $33(7 \%)$ of the 477 participants had 37 adenomas or cancers that were $10 \mathrm{~mm}$ or larger, and three participants had three adenocarcinomas that were 10 mm or larger. Nonadenomatous lesions that were $5 \mathrm{~mm}$ or larger included 44 hyperplastic polyps $(26 \%)$ and four lipomas (2\%); eight lesions (5\%) showed other histologic findings. In total, 167 lesions measuring $5 \mathrm{~mm}$ in diameter or larger were detected at colonoscopy.

\section{Individual Polyp Assessment}

The sensitivity of CT colonography in the two age groups for the detection of adenomas or cancers with varying sizes is shown in Table 4 . In the older group, the average sensitivity estimate for detection of adenomas or cancers $10 \mathrm{~mm}$ or larger was 0.75 (95\% CI: 0.578, 0.869), compared with 0.84 (95\% CI: 0.717, 0.924 ) in the younger group. There was no difference in per-polyp sensitivity estimates between the age groups.

\section{Preparation and Distention}

Among the 477 participants in the older age group, colon preparation involved polyethylene glycol solution for 224 participants $(47 \%)$, sodium phosphate solution $(90 \mathrm{~mL})$ for 225 participants (47\%), magnesium citrate for 26 participants $(5 \%)$, and "other" for two participants $(<1 \%)$. Barium sulfate for fecal tagging and iodinated contrast material for fluid tagging were taken as directed by 468 (98\%) and 447 (94\%) of the participants, respectively. Glucagon was administered to 430 participants (90\%); however, it was not administered to 23 participants with brittle diabetes mellitus, to one with a borderline glucose level, to 16 who declined, and to seven for whom the drug was not available.

Polyethylene glycol was prescribed in a significantly greater proportion of the older participants (224 [47\%] of $477)$ than the younger participants (796 


\section{Table 2}

\section{Comparison of Age-estimated Per-Participant Accuracy in Detecting Adenomas or Cancers at CT Colonography}

\begin{tabular}{|c|c|c|c|c|c|c|}
\hline \multirow[b]{2}{*}{ Performance Measure } & \multicolumn{6}{|c|}{ Adenoma or Cancer Size (mm) } \\
\hline & $\geq 5$ & $\geq 6$ & $\geq 7$ & $\geq 8$ & $\geq 9$ & $\geq 10$ \\
\hline \multicolumn{7}{|l|}{ Sensitivity } \\
\hline Age $\geq 65 y$ & $\begin{array}{r}0.599(0.455 \\
0.742)[77]\end{array}$ & $\begin{array}{r}0.715(0.565 \\
0.854)[60]\end{array}$ & $\begin{array}{r}0.771(0.603 \\
0.881)[47]\end{array}$ & $\begin{array}{r}0.773(0.603 \\
0.879)[41]\end{array}$ & $\begin{array}{r}0.821(0.644, \\
0.933)[33]\end{array}$ & $\begin{array}{r}0.821(0.644 \\
0.944)[33]\end{array}$ \\
\hline Age $<65 y$ & $\begin{array}{r}0.670(0.596 \\
0.737)[205]\end{array}$ & $\begin{array}{c}0.813(0.745 \\
0.882)[150]\end{array}$ & $\begin{array}{c}0.842(0.766 \\
0.893)[127]\end{array}$ & $\begin{array}{l}0.871(0.788 \\
0.929)[113]\end{array}$ & $\begin{array}{r}0.907(0.831 \\
0.960)[87]\end{array}$ & $\begin{array}{r}0.915(0.837 \\
0.967)[76]\end{array}$ \\
\hline Change & $\begin{array}{l}-0.070(-0.216 \\
0.081)\end{array}$ & $\begin{array}{l}-0.097(-0.242 \\
0.041)\end{array}$ & $\begin{array}{l}-0.077(0.220, \\
0.043)\end{array}$ & $\begin{array}{l}-0.105(-0.261 \\
0.027)\end{array}$ & $\begin{array}{l}-0.092(-0.251 \\
0.044)\end{array}$ & $\begin{array}{l}-0.100(-0.289 \\
0.051)\end{array}$ \\
\hline \multicolumn{7}{|l|}{ Specificity } \\
\hline Age $\geq 65 y$ & $\begin{array}{c}0.859(0.804 \\
0.904)[400]\end{array}$ & $\begin{array}{l}0.858(0.801 \\
0.906)[417]\end{array}$ & $\begin{array}{l}0.847(0.787 \\
0.897)[430]\end{array}$ & $\begin{array}{r}0.837(0.779 \\
0.885)[436]\end{array}$ & $\begin{array}{c}0.834(0.779 \\
0.881)[444]\end{array}$ & $\begin{array}{l}0.834(0.779 \\
0.883)[444]\end{array}$ \\
\hline Age $<65 y$ & $\begin{array}{l}0.893(0.858 \\
0.924)[1849]\end{array}$ & $\begin{array}{l}0.885(0.844 \\
0.919)[1904]\end{array}$ & $\begin{array}{l}0.878(0.836 \\
0.912)[1927]\end{array}$ & $\begin{array}{l}0.874(0.831 \\
0.910)[1941]\end{array}$ & $\begin{array}{l}0.865(0.820 \\
0.901)[1967]\end{array}$ & $\begin{array}{l}0.862(0.816 \\
0.899)[1978]\end{array}$ \\
\hline Change & $\begin{array}{l}-0.034(-0.068 \\
0.002)\end{array}$ & $\begin{array}{l}-0.027(-0.059 \\
0.008)\end{array}$ & $\begin{array}{l}-0.032(-0.065, \\
0.004)\end{array}$ & $\begin{array}{c}-0.037(-0.067 \\
-0.002)^{\star}\end{array}$ & $\begin{array}{l}-0.032(-0.062 \\
0.003)\end{array}$ & $\begin{array}{l}-0.028(-0.059 \\
0.007)\end{array}$ \\
\hline \multicolumn{7}{|l|}{ Positive predictive value } \\
\hline Age $\geq 65$ y $(n=100)$ & $0.489(0.361,0.620)$ & $0.470(0.342,0.604)$ & $0.411(0.278,0.562)$ & $0.354(0.246,0.477)$ & $0.329(0.216,0.461)$ & $0.329(0.216,0.459)$ \\
\hline Age $<65$ y $(n=323)$ & $0.433(0.364,0.499)$ & $0.371(0.306,0.434)$ & $0.313(0.239,0.383)$ & $0.287(0.216,0.356)$ & $0.224(0.169,0.277)$ & $0.203(0.154,0.253)$ \\
\hline Change & $\begin{array}{l}0.056(-0.103 \\
0.227)\end{array}$ & $\begin{array}{l}0.098(-0.053 \\
0.262)\end{array}$ & $\begin{array}{l}0.098(-0.076 \\
0.300)\end{array}$ & $\begin{array}{l}0.067(-0.081 \\
0.238)\end{array}$ & $\begin{array}{l}0.105(-0.033 \\
0.266)\end{array}$ & $\begin{array}{l}0.126(-0.008 \\
0.279)\end{array}$ \\
\hline \multicolumn{7}{|l|}{ Negative predictive value } \\
\hline Age $\geq 65$ y $(n=377)$ & $0.912(0.881,0.942)$ & $0.947(0.923,0.970)$ & $0.967(0.946,0.985)$ & $0.973(0.957,0.987)$ & $0.984(0.972,0.995)$ & $0.984(0.972,0.995)$ \\
\hline Age $<65$ y $(n=1731)$ & $0.963(0.951,0.972)$ & $0.984(0.979,0.989)$ & $0.990(0.986,0.994)$ & $0.993(0.988,0.997)$ & $0.996(0.992,0.999)$ & $0.996(0.993,0.999)$ \\
\hline Change & $\begin{array}{l}-0.051(-0.082 \\
-0.022)^{\star}\end{array}$ & $\begin{array}{l}-0.036(-0.060 \\
-0.014)^{\star}\end{array}$ & $\begin{array}{l}-0.023(-0.042 \\
-0.007)^{\star}\end{array}$ & $\begin{array}{l}-0.019(-0.035 \\
-0.006)^{\star}\end{array}$ & $\begin{array}{l}-0.011(-0.023 \\
-0.001)^{\star}\end{array}$ & $\begin{array}{l}-0.012(-0.024 \\
-0.001)^{\star}\end{array}$ \\
\hline
\end{tabular}

Note.-Data in parentheses are $95 \%$ Cls, with numbers of participants in brackets.

* The $95 \% \mathrm{Cl}$ does not include 0 , indicating an uncorrected significant difference at the $\alpha$ level of .05 .

[39\%] of 2054), an 8\% significant difference (95\% CI: $3.2 \%, 13.2 \%)$. Sodium phosphate was prescribed in a significantly smaller proportion of the older participants $(n=225 ; 47 \%)$ than the younger participants $(n=1178 ; 57 \%)$, a $10 \%$ significant difference (95\% CI: $5.2 \%, 15.1 \%)$. The proportion of participants receiving magnesium citrate was not significantly different between the older population $(n=26 ; 5.5 \%)$ and the younger population $(n=76 ; 3.7 \%)$ (95\% CI: $-0.4 \%, 3.9 \%)$.

Optimal colon distention (ie, a wellvisualized colon) was recorded more frequently in the younger population (1354 [66\%] of 2054) than the older population (264 [55\%] of 477), a significant difference of $11 \% \quad(95 \%$ CI: $5.7 \%, 15.5 \%$ ), as were optimal ratings (ie, none or minimal) for the amount of retained colonic fluid (younger population, 1133 [55\%] of 2054; older population, 222 [46\%] of 477), with a significant difference of $9 \%$ (95\% CI: $3.7 \%$, 13.6\%). Optimal ratings (none or small particles) for residual stool were more frequent in the younger population (1791 [87\%] of 2054) than the older population (409 [86\%] of 477), a nonsignificant difference of $2 \%$ (95\% CI: $2.0 \%, 4.9 \%)$. Overall, optimal bowel assessment was more frequent in the younger population (735 [36\%] of 2054) than the older population (125 [26\%] of 477), a significant difference of $10 \%$ (95\% CI: $5 \%, 14 \%$ ). There was no significant difference in the prevalence of right- and left-sided lesions between the two study groups (Table 3).

Adverse events (grade 3 [severe] or higher, including nausea, vomiting, infection, and hemorrhage) were reported for two participants in the older population. One participant had excessive bleeding after snare polypectomy and was hospitalized for 2 days of observation. The other participant was hospitalized for Escherichia coli bacteremia diagnosed 24 hours after both procedures.

\section{Extracolonic Findings}

Extracolonic findings were observed in $387(81 \%)$ of the 477 participants aged 65 years or older, compared with $1278(62 \%)$ of the 2054 younger participants. However, of the older participants, some were deemed to require additional evaluation (100 [21\%] of 477 ) or urgent care (four [0.8\%] of 477) for at least one finding compared with the younger participants (additional evaluation, 298 [15\%] of 2054 ; urgent care, 26 [1.3\%] of 2054). For these 100 participants in the older cohort, 107 findings were categorized by the reporting radiologist as requiring additional evaluation (including correlation with history or prior imaging 
Table 3

\section{Distribution of Lesions 10 mm or Larger as Detected at Optical Colonoscopy}

\begin{tabular}{|c|c|c|}
\hline Bowel Segment and Lesion Histologic Type & Participants $<65$ y & Participants $\geq 65 \mathrm{y}$ \\
\hline \multicolumn{3}{|l|}{ Rectum } \\
\hline Adenoma or carcinoma & 18 (19.78) & 7 (18.92) \\
\hline Nonadenomatous lesion & $2(13.33)$ & $5(41.67)$ \\
\hline \multicolumn{3}{|l|}{ Sigmoid } \\
\hline Adenoma or carcinoma & $27(29.67)$ & $5(13.51)$ \\
\hline Nonadenomatous lesion & $2(13.33)$ & $2(16.67)$ \\
\hline \multicolumn{3}{|l|}{ Descending } \\
\hline Adenoma or carcinoma & $4(4.40)$ & $4(10.81)$ \\
\hline Nonadenomatous lesion & $1(6.67)$ & $1(8.33)$ \\
\hline \multicolumn{3}{|l|}{ Transverse } \\
\hline Adenoma or carcinoma & $12(13.19)$ & $5(13.51)$ \\
\hline Nonadenomatous lesion & $3(20.00)$ & $1(8.33)$ \\
\hline \multicolumn{3}{|l|}{ Ascending } \\
\hline Adenoma or carcinoma & $19(20.88)$ & $8(21.62)$ \\
\hline Nonadenomatous lesion & $5(33.33)$ & $2(16.67)$ \\
\hline \multicolumn{3}{|l|}{ Cecum } \\
\hline Adenoma or carcinoma & $11(12.09)$ & $8(21.62)$ \\
\hline Nonadenomatous lesion & $2(13.33)$ & $1(8.33)$ \\
\hline \multicolumn{3}{|l|}{ Total } \\
\hline Adenoma or carcinoma & $91(100)$ & $37(100)$ \\
\hline Nonadenomatous lesion & $15(100)$ & $12(100)$ \\
\hline \multicolumn{3}{|l|}{ Left colon (rectum, sigmoid, descending)* } \\
\hline Adenoma or carcinoma ${ }^{\dagger}$ & $49(53.85)$ & $16(43.24)$ \\
\hline Nonadenomatous lesion $\ddagger$ & $5(33.33)$ & $8(66.67)$ \\
\hline \multicolumn{3}{|l|}{ Right colon (transverse, ascending, cecum)* } \\
\hline Adenoma or carcinoma $^{\dagger}$ & $42(46.15)$ & $21(56.76)$ \\
\hline Nonadenomatous lesion ${ }^{\ddagger}$ & $10(66.67)$ & $4(33.33)$ \\
\hline \multicolumn{3}{|c|}{$\begin{array}{l}\text { Note-Data are numbers of lesions, with percentages in parentheses. Patients younger than } 65 \text { years had a total of } 91 \\
\text { adenomas or carcinomas of } 10 \mathrm{~mm} \text { or larger and a total of } 15 \text { nonadenomatous lesions of } 10 \mathrm{~mm} \text { or larger; patients } 65 \text { years } \\
\text { of age or older had a total of } 37 \text { adenomas or carcinomas of } 10 \mathrm{~mm} \text { or larger and a total of } 12 \text { nonadenomatous lesions of } 10 \\
\mathrm{~mm} \text { or larger. }\end{array}$} \\
\hline \multicolumn{3}{|c|}{ * The difference between all left- and right-colon lesions was not significant by age $(P=.83)$} \\
\hline \multicolumn{3}{|c|}{${ }^{\dagger}$ The difference between left- and right-colon adenomas or carcinomas was not significant by age $(P=.30)$. } \\
\hline ‡ The difference between left- and right-colon no & sions was not significan & \\
\hline
\end{tabular}

studies) or urgent care. These findings were located in the chest (36 [34\%] of 107), gastrointestinal tract (19 [18\%] of 107), genitourinary tract (31 [29\%] of 107), vascular system (12 [11\%] of 107), and musculoskeletal system (two [2\%] of 107). Information on actual management or history regarding these extracolonic findings was not collected. Therefore, some of these findings could have been previously known and already properly treated.

\section{Discussion}

The present post-hoc analysis of the data for participants aged 65 years or older and the comparison with participants younger than 65 years was not part of the original protocol of the $\mathrm{Na}^{-}$ tional CT Colonography Trial (1). Considerations for such an analysis did not enter into the sample size calculations of the study. Thus, the results of this analysis should be interpreted as exploratory. Our data analysis comparing two subgroups from the larger study did not find significant differences in the diagnostic accuracy of CT colonography for detecting large ( $\geq 10$-mm) asymptomatic colorectal neoplasia in participants 65 years of age or older compared with that in participants younger than 65 years. Furthermore, our analysis did not find significant differences in sensitivity and specificity for smaller (6-9-mm) colorectal neoplasia.

A statistically significant difference did exist in the negative predictive value for all size lesions tested. Because this was a screening study, the vast majority of examinations were negative for polyps $5 \mathrm{~mm}$ or larger. Furthermore, within this large study, 2108 participants were considered for this measure. Small differences with large numbers of participants can become statistically significant, even though these differences may not represent a clinically important difference. Across the various polyp sizes, the differences in negative predictive value between the older and younger age groups varied between 0.051 and 0.012 . The differences became less as polyp size increased. For large adenomas, the negative predictive value varied between 0.984 and 0.996-a difference unlikely to change the clinical care of a patient. Therefore, we believe that these statistical differences in negative predictive value do not represent a clinically important difference.

The percentage of participants with large adenomas was significantly greater among older participants in our study $(3.7 \%$ of participants aged $<65$ years had large adenomas vs $6.9 \%$ of those aged $\geq 65$ years; $P<.004$ ). A greater percentage of radiologists detected all of the large adenomas than detected the adenomas of the entire cohort. Overall, there was a nonsignificant decrease in examination performance for the older participant cohort.

Differences in type of colon preparation between the younger and older participant groups are understandable, because sodium phosphate is avoided in patients with comorbidities, especially heart and renal diseases. Many physicians today avoid the sodium phosphate preparation entirely. The polyethylene glycol preparation is commonly associated with retained colonic fluid and is the likely cause of an increase in such retention. Retained fluid is a primary reason for the use of fluid tagging in the preparation protocol for all patients. 


\section{Table 4}

\section{Comparing Per-Polyp Estimates of Sensitivity of CT Colonography for Detection of Adenomas and Cancers}

\begin{tabular}{|c|c|c|c|c|c|c|}
\hline \multirow[b]{2}{*}{ Parameter } & \multicolumn{6}{|c|}{ Size of Adenoma or Cancer (mm) } \\
\hline & $\geq 5$ & $\geq 6$ & $\geq 7$ & $\geq 8$ & $\geq 9$ & $\geq 10$ \\
\hline Participant age $\geq 65$ y & $\begin{array}{c}0.497(0.368 \\
0.634) \text { [111] }\end{array}$ & $\begin{array}{r}0.590(0.443 \\
0.735)[80]\end{array}$ & $\begin{array}{r}0.694(0.528 \\
0.800)[60]\end{array}$ & $\begin{array}{r}0.706(0.548 \\
0.803)[48]\end{array}$ & $\begin{array}{r}0.755(0.588 \\
0.872)[38]\end{array}$ & $\begin{array}{r}0.755(0.578 \\
0.869)[37]\end{array}$ \\
\hline Participant age $<65$ y & $\begin{array}{l}0.598(0.527 \\
0.660)[263]\end{array}$ & $\begin{array}{l}0.722(0.640 \\
0.802)[190]\end{array}$ & $\begin{array}{c}0.740(0.638 \\
0.798)[160]\end{array}$ & $\begin{array}{l}0.793(0.687 \\
0.860)[139]\end{array}$ & $\begin{array}{l}0.825(0.709 \\
0.902)[105]\end{array}$ & $\begin{array}{r}0.839(0.717 \\
0.924)[91]\end{array}$ \\
\hline Change & $\begin{array}{l}-0.101(-0.216 \\
0.010)\end{array}$ & $\begin{array}{l}-0.133(-0.263 \\
-0.014)^{*}\end{array}$ & $\begin{array}{l}-0.050(-0.217 \\
0.106)\end{array}$ & $\begin{array}{l}-0.094(-0.255 \\
0.049)\end{array}$ & $\begin{array}{l}-0.074(-0.252 \\
0.091)\end{array}$ & $\begin{array}{c}-0.091(-0.289, \\
0.085)\end{array}$ \\
\hline
\end{tabular}

Note.-Data are average sensitivities, with $95 \% \mathrm{Cls}$ in parentheses and numbers of lesions in brackets.

* The $95 \% \mathrm{Cl}$ does not include 0 , indicating an uncorrected significant difference at the $\alpha$ level of .05 .

Poorer colon distention in the older group was noted despite use of a mechanical insufflator. This finding could be due to such factors as an incompetent ileocecal valve, poorer sphincter control, more advanced cases of diverticulosis and muscular hypertrophy, or more difficult patient rotation on the CT table. Awareness of this result could be managed by slower insufflation of the colon and vigilant review of the scout images before scanning. Additional decubitus views might also be helpful. The increased percentage of retained stool in the older group would be an issue common to colonoscopy as well. The use of stool tagging at CT colonography would be especially important in the older group so that retained stool could be discriminated easily from soft-tissueattenuation polyps. Despite these differences in the amount of colonic distention, fluid, and stool between the two groups, there was no significant difference in examination performance. This finding indicates that the differences in preparation did not cause a clinically important problem in examination quality. Likely, the fluid tagging and stool tagging were helpful in ensuring a diagnostic-quality examination.

Low-dose CT colonography with a $50 \%$ reduction in radiation dose compared with standard CT of the abdomen and pelvis was used in both participant groups. This lower dose was possible because of the high contrast between the gas-distended colon lumen and the softtissue-attenuation colon wall. The position paper of the Health Physics Society (6) indicates that at a radiation exposure of the magnitude administered for a single CT colonography examination (the mean effective dose for an averagesized patient is equivalent to 5.0-6.5 $\mathrm{mSv})$, the radiation risk is too small to measure or is nonexistent. Even assuming a small risk of radiation-induced cancers, this issue becomes less relevant for older individuals because a long latency period ( $>20$ years) is required between the exposure and the theoretical risk of a malignancy. In contrast, the real risks of patients undergoing optical colonoscopy are well documented. Recently, Kim et al (7) similarly reported in patients aged 65 years and older the prevalence of potentially important extracolonic findings of $15.4 \%$, with a work-up rate of $7.8 \%$. The prevalence of extracolonic findings in this study was not significantly different between the group aged 65 years or older and the general screening group. In this study two adverse events occurred, one of which was clearly secondary to colonoscopic polypectomy. Both participants recovered without surgical intervention.

Not surprisingly, the prevalence of extracolonic findings increased with age. Although these findings have the potential to incur additional testing, cost, and patient concern, their benefits also need to be considered. Radiologists need to develop algorithms for appropriate management of these findings so that the costs of additional medical care are controlled (8). However, the actual incidence of additional participant work-up is unknown in the present study and likely is low generally (9), because many important extracolonic findings are known before the CT colonography examination and are already adequately managed.

The overall prevalence of large adenomas and cancers in the study population was $6.9 \%$, indicating that most patients would not require therapeutic colonoscopy when 1-cm lesions are targeted. Even when adenomas $6 \mathrm{~mm}$ or larger are targeted for colonoscopy, the colonoscopy referral rate would not exceed $12.6 \%$.

Limitations of our study were twofold. First, the comparison of the performance of CT colonography in the two age cohorts was a secondary analysis in the study, and the needs for statistical power for this comparison were not considered in designing the original study. The primary study sought to understand the performance of CT colongraphy in a screening population overall (ie, in all participants $>50$ years). Second, some differences may exist between the study cohort and the population of persons age 50 or older who could be eligible for colonoscopy screening. In particular, the younger group may have needed employment insurance or self-pay insurance to cover colonoscopy screening charges to participate in the study, whereas the older population would have had Medicare insurance. Thus, the younger cohort may be of higher socioeconomic status than the general population of persons between 50 and 64 years of age. However, we note that invitations to participate were made to all of the participants scheduled for colonoscopic colorectal cancer screening, as long as they were 
50 years of age or older and were not precluded by the exclusion criteria. The insurance factors exist widely within the general U.S. population, and the populations that are compared are representative of most participants undergoing colorectal cancer screening today.

In summary, a post-hoc analysis of data from the National CT Colonography Trial did not find significant differences in the diagnostic accuracy of CT colonography for the detection of large and intermediate-size adenomatous lesions in participants 65 years of age and older compared with younger participants. Performance estimates observed in the present study were based on data in a subject population with predominately average risk and support CT colonography as a primary colorectal cancer screening tool for all eligible patients.

Acknowledgments: We are indebted to the many people at the headquarters of the American College of Radiology Imaging Network and at the recruiting sites for their important contributions to the study and to the radiologists, gastroenterologists, and research associates at the clinical sites. Complete list of authors: C. Daniel Johnson, MD, MMM; Benjamin A. Herman, SM; MeiHsiu Chen, PhD; Alicia Y. Toledano, ScD; Jay P. Heiken, MD; Abraham H. Dachman, MD; Mark D. Kuo, MD; Christine O. Menias, MD; Bettina Siewert, MD; Jugesh I. Cheema, MD; Richard G. Obregon, MD; Jeff L. Fidler, MD; Peter Zimmerman, MD; Karen M. Horton, MD; Kevin J. Coakley, MD; Revathy B. Iyer, MD; Amy K. Hara, MD; Robert A. Halvorsen, Jr, MD; Giovanna Casola, MD; Judy Yee, MD; Meredith Blevins, SM; Lawrence J. Burgart, MD; Paul J. Limburg, MD, MPH; and Constantine A. Gatsonis, PhD.

Author affiliations: Department of Radiology, Mayo Clinic, 13400 E Shea Blvd, Scottsdale, AZ 85259 (C.D.J., A.K.H.); Brown University Center for Statistical Sciences, Providence, RI (B.A.H., M.H.C., C.A.G.); Statistics Collaborative, Washington, DC (A.Y.T.); Mallinckrodt Institute of Radiology, Washington University School of Medicine, St Louis, Mo (J.P.H., C.O.M.); University of Chicago Medical Center, Chicago, III (A.H.D.); Scottsdale Medical Imaging, Scottsdale, Ariz (M.D.K.); Beth Israel Deaconess Medical Center, Boston, Mass (B.S.); Deaconess Hospital, Evansville, Ind (J.I.C.); Radiology Imaging Associates, Denver, Colo (R.G.O.); Department of Radiology (J.L.F.) and Division of Gastroenterology and Hepatology (P.J.L.), Mayo Clinic, Rochester, Minn; University of California Los Angeles, Los Angeles, Calif (P.Z.); Johns Hopkins University, Baltimore, Md (K.M.H.); Clinical Radiologists, Springfield, III (K.J.C.); University of Texas MD Anderson Cancer Center, Houston, Tex (R.B.I.); Department of Radiology, Medical College of Virginia, Virginia Commonwealth University, Richmond, Va (R.A.H.); University of California
San Diego, San Diego, Calif (G.C.); Department of Radiology and Biomedical Imaging, University of California San Francisco VA Medical Center, San Francisco, Calif (J.Y.); Department of Biostatistics, Vanderbilt University, Nashville, Tenn (M.B.); and Abbott Northwestern Hospital, Minneapolis, Minn (L.J.B.)

Author contributions: Guarantors of integrity of entire study, C.D.J., C.A.G.; study concepts study design or data acquisition or data analysis/ interpretation, all authors; manuscript drafting or manuscript revision for important intellectual content, all authors; manuscript final version approval, all authors; literature research C.D.J., B.A.H., G.C., P.J.L., C.A.G.; clinical studies, C.D.J., A.Y.T., J.P.H., A.H.D., M.D.K. C.O.M., B.S., J.I.C., R.G.O., J.L.F., P.Z., K.M.H., K.J.C., R.B.I., А.K.H., R.A.H., G.C., J.Y., L.J.B., C.A.G.; statistical analysis, B.A.H., M.H.C., A.Y.T., M.B., C.A.G.; and manuscript editing, C.D.J., B.A.H., M.H.C., J.P.H., A.H.D., R.G.O., J.L.F., P.Z., R.A.H., G.C., J.Y., L.J.B. P.J.L., C.A.G.

Disclosures of Potential Conflicts of Interest: C.D.J. Financial activities related to the present article: none to disclose. Financial activities not related to the present article: institution receives money from CT colonography software patents; institution receives royalties from GE Healthcare. Other relationships: none to disclose. B.A.H. No potential conflicts of interest to disclose. M.H.C. No potential conflicts of interest to disclose. A.Y.T. Financial activities related to the present article: none to disclose. Financial activities not related to the present article: institution receives money for consulting to a manufacturer of a CT colonography $\mathrm{CAD}$ product; institution receives money from manufacturers of other medical imaging devices. Other relationships: none to disclose. J.P.H. Financial activities related to the present article: none to disclose. Financial activities not related to the present article: is a consultant for Covidien; has patents or patents pending with Covidien and Medrad; receives royalties from Covidien. Other relationships: none to disclose. A.H.D. No potential conflicts of interest to disclose. M.D.K. No potential conflicts of interest to disclose. C.O.M. No potential conflicts of interest to disclose. B.S. No potential conflicts of interest to disclose. J.I.C. No potential conflicts of interest to disclose. R.G.O. No potential conflicts of interest to disclose. J.L.F. No potential conflicts of interest to disclose. P.Z. No potential conflicts of interest to disclose. K.M.H. No potential conflicts of interest to disclose. K.J.C. No potential conflicts of interest to disclose. R.B.I. No potential conflicts of interest to disclose. A.K.H. Financial activities related to the present article: none to disclose. Financial activities not related to the present article: institution receives royalties from GE Healthcare. Other relationships: none to disclose. R.A.H. No potential conflicts of interest to disclose. G.C. No potential conflicts of interest to disclose. J.Y. Financial activities related to the present article: none to disclose. Financial activities not related to the present article: institution has grants or grants pending with GE Healthcare for laxative-free CT colonography. Other relationships: none to disclose. M.B. No potential conflicts of interest to disclose. L.J.B. No potential conflicts of interest to disclose. P.J.L. Financial activities related to the present article: none to disclose. Financial activities not related to the present article: is a consultant for Genomic Health; institution has grants or grants pending with Olympus America, BENEO-Orafti, Bayer Health Care, Fujinon, Boston Scientific, and Astra Zeneca; has been paid for lectures by the American School of Oncology; receives royalties and stock or stock options, and institution receives royalties and stock or stock options, from Exact Sciences. Other relationships: none to disclose. C.A.G. Financial activities related to the present article: none to disclose. Financial activities not related to the present article: is a consultant for Wilex and Endocyte; has received payment from Bayer Health Care for conducting short courses on diagnostic imaging evaluation. Other relationships: none to disclose.

\section{References}

1. Johnson CD, Chen MH, Toledano AY, et al. Accuracy of CT colonography for detection of large adenomas and cancers. N Engl J Med 2008;359(12):1207-1217. [Published correc tion appears in N Engl J Med 2008;359(26): 2853.]

2. Levin B, Lieberman DA, McFarland B, et al, Screening and surveillance for the early detection of colorectal cancer and adenomatous polyps, 2008: a joint guideline from the American Cancer Society, the US Multi-Society Task Force on Colorectal Cancer, and the Ameri can College of Radiology. CA Cancer J Clin 2008;58(3):130-160.

3. BlueCross BlueShield Association. Technology evaluation center. BlueCross BlueShield http://www.bcbs.com/blueresources/tec/tec assessments.html. Published August 2009. Accessed September 1, 2010

4. Centers for Medicare \& Medicaid Services. Decision memo for screening computed tomography colonography (CTC) for colorectal cancer (CAG-00396N). Centers for Medicare and Medicaid Services. http:// www.cms.hhs.gov/mcd/viewdecisionmemo aspx? NCAId=220\&over. Published May 12, 20. Accessed September 1, 2010.

5. Efron B, Tibshirani RJ. An introduction to the bootstrap. New York, NY: Chapman \& Hall/ CRC, 1993.

6. Health Physics Society. Radiation risk in perspective: position statement of the Health Physics Society. http://hps.org/documents/risk _ps010-2.pdf. Adopted January 1996. Revised July 2010. Accessed September 13, 2010.

7. Kim DH, Pickhardt PJ, Hanson ME, Hinshaw JL. CT colonography: performance and program outcome measures in an older screening population. Radiology 2010;254(2):493-500.

8. Berland LL. Incidental extracolonic findings on CT colonography: the impending deluge and its implications. J Am Coll Radiol 2009;6(1):14-20.

9. Pickhardt PJ, Hanson ME, Vanness DJ, et al. Unsuspected extracolonic findings at screen ing CT colonography: clinical and economic impact. Radiology 2008;249(1):151-159. 